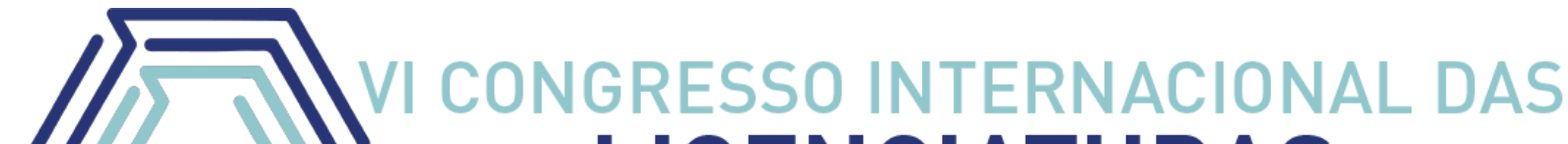 LICENCIATURAS COINTER - PDVL 2019
}

\section{A ARBORIZAÇÃO URBANA COMO FERRAMENTA INTERDISCIPLINAR PARA DISCENTES DE UMA ESCOLA LOCALIZADA NO MUNICÍPIO DE URUÇUÍ - PI}

\section{ARBORIZACIÓN URBANA COMO HERRAMIENTA INTERDISCIPLINARIA PARA ESTUDIANTES DE UNA ESCUELA UBICADA EN URUÇUÍ - PI}

\section{URBAN ARBORIZATION AS AN INTERDISCIPLINARY TOOL FOR STUDENTS OF A SCHOOL LOCATED IN URUÇUÍ - PI \\ Apresentação: Pôster}

\begin{abstract}
Martin Darley Pereira dos Santos ${ }^{1}$; Bianca Gomes dos Santos ${ }^{2}$; Gildenir da Silva Borges ${ }^{3}$; Tamires Carreiro Carvalho ${ }^{4}$ ícaro Fillipe de Araújo Castro ${ }^{5}$
\end{abstract}

\section{DOI: https://doi.org/10.31692/2358-9728.VICOINTERPDVL.2019.0125}

\section{Introdução}

Nos dias atuais, grande parte da população mundial vive em cidades, caracterizadas pela ocupação de edificações contínuas. Em consequência disso, alguns fatores são afetados pelas condições artificiais do meio urbano, como alterações climáticas que acarretam no aumento da intensidade da radiação solar, temperaturas elevadas, a umidade relativa do ar, a precipitação e a circulação do ar, alterando assim a sensação de conforto e desconforto das pessoas (CEMIG, 2011).

A arborização urbana é um componente importante para a melhoria da qualidade ambiental, auxiliando na obtenção de níveis suficientes de qualidade de vida e viabilizando efeitos psicológicos e físicos positivos sob a população. Além do mais, a arborização urbana contribui com melhorias de conforto aos habitantes das cidades, sendo que, com as plantas existe uma maior estabilização climática, embelezamento das vias e provimento de abrigo e alimento à fauna existente da região(McHALE et al., 2007).

\footnotetext{
${ }^{1}$ Discente do curso de Licenciatura em Ciências Biológicas do Instituto Federal do Piauí - IFPI, darleymartinsantos@gmail.com;

${ }^{2}$ Discente do curso de Licenciatura em Ciências Biológicas do Instituto Federal do Piauí - IFPI, biancabg2017@gmail.com;

${ }^{3}$ Discente do curso de Licenciatura em Ciências Biológicas do Instituto Federal do Piauí - IFPI, gsbsilva.1087@gmail.com;

${ }^{4}$ Discente do curso de Licenciatura em Ciências Biológicas do Instituto Federal do Piauí - IFPI, tamirescarreiro_12345@hotmail.com;

5 Mestrado em Biologia Celular e Molecular Aplicada da Universidade de Pernambuco-UPE, icaro.castro@ifpi.edu.br
} 
Estas árvores quando plantadas para promover o embelezamento do ambiente, adequando-se aos espaços livres, podem fortalecero contato homem-natureza de forma efetiva, além de promover uma maior estabilização climática, embelezamento das vias e provimento de abrigo e alimento à fauna existente da região. Além disso, a arborização urbana pode ser trabalhada com discentes da educação básica, promovendo o entendimento destes componentes arbóreos para o ambiente, bem como trabalhando temas relacionados a educação ambiental.

A Educação Ambiental é transformadora de valores e atitudes, e busca uma ética sensibilizadora e conscientizadora para as relações entre o ser humano, a sociedade e a natureza. Seu objetivo deve ser primeiramente relacionado ao aspecto local e, consecutivamente global, assegurando a existência das mais diversas formas de vida. Os termos educação e ambiental sugerem uma reavaliação do modo de vida. Portanto, a educação ambiental surge devido à urgente necessidade de configurarmos nossas escolhas, valores, paradigmas e modelos de desenvolvimento e de sociedade (GUIMARÃES, 2007).

Devido suas diversas funções, a arborização urbana engloba grandes contribuições para manter o bem-estar físico e emocional da população, visto que, tem grande importância para o alcance dos níveis de qualidade de vida nos centros urbanos. Nesse contexto, o objetivo do presenteestudo foi realizar um diagnóstico preliminar da arborização urbana da cidade de Uruçuí - PI com alunos do $3^{\circ}$ ano de uma escola estadual de Uruçuí-PI, identificandoas principais espécies introduzidas e adotadas na arborização urbana desse município, bem como trabalhando a interdisciplinaridade das disciplinas de matemática, geografia e biologia, visando principalmente a educação ambiental.

\section{Fundamentação Teórica}

\section{Arborização urbana}

A arborização urbana pode evitar ilhas de calor, desertos biológicos e o desconforto ambiental.Apesar disso, a arborização realizadaem muitas cidadescom o uso de poucas espécies e ainda de forma descontínua, o que gera perda de biodiversidade, uma vez que estas têm função de abrigo e alimentação, e assim apenas poucas espécies conseguem sobreviver em áreas urbanas (VRUN; LINKY; VRUN, 2007).

No Brasil, usa-se geralmente plantas exóticas e com pouca fenologia conhecida para a ornamentação em ambientes paisagísticos (LORENZI; SOUZA, 2001). Apesar de que essas 
plantas sirvam para melhorar a beleza cênica dos ambientes urbanos, essas também podem ocasionar problemas quando as escolhas e plantações são inadequadas ao lugar que são inseridas. Em geral, as plantas selecionadas para o plantio, são analisadas apenas suas características estéticas, sendo incompreendido características importantes como localização de origem, forma do caule, formato da coroa, velocidade de propagação e crescimento, entre outros aspectos. (HEIDEN et al., 2006; ZILLER, 2006).

Diante desses fatos, durante a implementação de planejamentos de plantio dessas árvores, deve-se levar em consideração a quantidade de plantas que podem ser utilizadas por área. Segundo Santos et al (2017), o plantio não deve exceder 10\% da mesma espécie, 20\% de algum gênero e 30\% de uma família botânica, e que essas sejam adaptadas as condições ambientais locais e que possibilitem a realização de podas, para evitar que atinjam as fiações elétricas.

\section{Educação ambiental}

É fundamental que a população perceba melhor o espaço natural que ocupa, inclusive o presente nos centros urbanos e veja neles recursos fundamentais para biodiversidade e assim contribuam para a sua preservação. A consolidação da cidadania está diretamente ligada a uma prática social que respalde os direitos do meio ambiente e que ponha em destaque um diálogo ímpar com a natureza. Dessa forma, a cidadania ambiental só pode ser construída a partir de um processo educativo de larga abrangência, envolvendo a alteração do processo de seleção das informações, e compreendendo a dinâmica do mútuo enriquecimento entre o natural e a humano (LIMA et al., 2017).

A destruição e/ou poluição dos recursos naturais, bem como suas consequências, tem sido cada vez mais evidentes no mundo globalizado. Nesse contexto, a Educação Ambiental (EA) é vista como uma atividade importante para a formação de um novo perfil de cidadão que deve ser muito mais atento aos problemas vigentes e que saiba conduzir suas ações respaldadas em uma prática ecológica e sustentável (GALVÃO e MAGALHÃES-JÚNIOR, 2016).

\section{Metodologia}

Essa pesquisa foi realizada por meio de um estudo de abordagem qualitativa, de natureza descritiva exploratória, realizada com 25 discentes do $3^{\circ}$ ano do ensino médio com 
idade entre 15 e 17 anos, sendo 15 alunos do sexo masculino e 10 alunos do sexo feminino de uma escola estadual situada no município de Uruçuí-PI e contou com a participação dos professores de três disciplinas (geografia, matemática e biologia), o que fortalece o cunho interdisciplinar desse trabalho.

Em sua primeira parte, o professor de geografia ministrou uma aula sobre o bioma Cerrado (bioma característico da região), bem como plantas nativas e exóticas. Além disso, houve pesquisa na sala de informática sob a supervisão do professor de geografia pelos próprios alunos. Posteriormente foi realizada uma aula de campo exploratória para se fazer a observação, coleta de dados e quantificação das espécies arbóreas com os estudantes participantes da pesquisa.

Essa parte do projeto foi realizada no canteiro de plantas da avenida Coronel Rogério

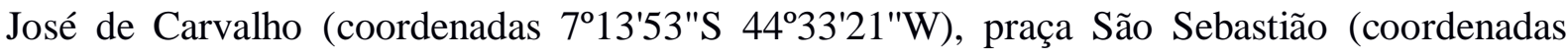
$7^{\circ} 13 ' 50 " S 4^{\circ} 33^{\prime} 17^{\prime \prime} W$ ) e praça da Igreja Nova de São Sebastião (coordenadas $7^{\circ} 14^{\prime} 14^{\prime \prime S}$ $\left.44^{\circ} 33^{\prime} 23^{\prime \prime} \mathrm{W}\right)$, sendo esses espaços caracterizados como principal avenida e praças do município de Uruçuí-PI, respectivamente.

O levantamento das espécies foi realizado no mês de maio de 2019, por meio de caminhadas exploratórias com os alunos do $3^{\circ}$ ano da escola núcleo do Pibid - Centro de Ensino Médio Jornada Ampliada - Cicero Coelho, onde nestes locais foi observado todos espécimes de indivíduos vegetais com porte arbóreo plantados, sendo recolhidos algumas partes (flor, folha, fruto) para auxiliar na identificação, e cada espécie foi fotografada no seu habitat de ocorrência, e esse material fotográfico serviu como complemento às informações de campo.

Após a coleta dos dados quantitativos, a professora de matemática ministrou uma aula para auxiliar os alunos na quantificação percentual do número de espécies encontradas nas caminhadas exploratórias. Na aula de biologia posterior, o professor da disciplina usou a sua aula para trabalhar de forma teórica temas relacionados a biodiversidade de animais urbanos que se utilizam dos espécimes arbóreos presentes na cidade, bem como a importância das árvores não somente para estes animais como para a biodiversidade em geral, estimulando nos alunos ideias de preservação desses recursos e trabalhando diretamente a educação ambiental.

$\mathrm{Na}$ aula seguinte de biologia, os alunos do $3^{\circ}$ ano da escola núcleo juntamente com os pibidianos realizaram as identificações das espécies a partir de chaves de identificação das bibliografias botânicas e da consulta a especialistas. Os nomes vernaculares foram mantidos 
na grafia local. Ao final os alunos dos três grupos apresentaram a turma inteira, o que foi observado, espécies, quantidade, diversidade e problemas ocasionados por algumas árvores.

\section{Resultados e Discussões}

O trabalho de campo foi executado conforme especificado no percurso metodológico, por meio da observação e identificação das espécies presentes no canteiro central da Avenida Coronel Rogério José de Carvalho, na Praça da Igreja Nova de São Sebastião e Praça São Sebastião em Uruçuí - PI. Com as bibliografias específicas, foram feitas apresentações, análises e identificação das espécies catalogadas. As espécies arbóreas catalogadas foram:

Tabela 1. Espécies arbóreas de maior ocorrência dos espaços investigados no estudo.

\begin{tabular}{ccccc} 
Nome científico & Nome comum & Quantidade & Porcentagem & Origem \\
\hline Mangifera indica & Mangueira & 25 & $29 \%$ & Nativa \\
\hline Sabal palmetto & Palmeira & 23 & $26 \%$ & Exótica \\
\hline Tabebuia ochracea & Ipê-do-cerrado & 20 & $23 \%$ & Nativa \\
\hline Copernicia prunifera & Carnaúba & 06 & $7 \%$ & Exótica \\
\hline Azadirachta indica & Nim & 05 & $6 \%$ & Exótica \\
\hline Terminalia catappa & $\begin{array}{c}\text { Amendoeira-da- } \\
\text { praia }\end{array}$ & 04 & $5 \%$ & Exótica \\
\hline $\begin{array}{c}\text { Anacardium } \\
\text { occidentale }\end{array}$ & $\begin{array}{c}\text { Cajueiro } \\
\text { Citrus } X \text { sinensis }\end{array}$ & 01 & $1 \%$ & Nativa \\
\hline Syzygium jambos & Jambeiro & 01 & $1 \%$ & Nativa \\
\hline Jasminum sabac & Jasmim - árabe & 01 & $1 \%$ & Exótica \\
\hline Fonte: Propia & 01 & $1 \%$ & Exótica \\
\hline
\end{tabular}

Fonte: Própria (2019)

Além disso, constatou-se o empenho dos estudantes na identificação de tais espécies, principalmente pela apresentação dos grupos em sala de aula no qual destacaram brilhantemente o papel das espécies arbóreas no ambiente urbano, distinguiram espécies exóticas e nativas e evidenciaram diversos fatores para preservação desses organismos relacionando principalmente a dependência da fauna às áreas verdes.

Paiva et al., (2010) realizaram o levantamento e diagnóstico da arborização viária dentro do perímetro urbano da cidade de Rio Branco-AC, e destacaram em seu estudo a importância do desenvolvimento da educação ambiental, visando sensibilizar a população sobre a importância da arborização urbana, principalmente pelos seus serviços ambientais, para envolvê-la efetivamente no processo, e garantir a redução da depredação, bem como o seu pleno desenvolvimento.

Além disso, em uma roda de conversa realizada ao final das apresentações, os 
discentes comentaram que gostaram muito da atividade em questão, destacando-se a fala de um aluno: "essas idas as praças são muito legais, pois conseguimos ver melhor a natureza que muitas vezes não vemos e também podemos olhar de perto sua importância pra todo mundo de uma cidade cheia de árvores".

\section{Conclusões}

A partir dos espécimes identificados, observou-se pelos discentes que muitas árvores não são pertencentes a flora nativa do cerrado, sendo espécies exóticas usadas frequentemente na arborização. Além disso, esse trabalho contribuiu para a aprendizagem dos alunos em várias áreasdo conhecimento(como biologia, geografia, matemática e a educação ambiental) de forma que estes puderam fortalecer seus conceitos a respeito das plantas em geral e do Cerrado. Além disso, perceberam a importância das árvores nos espaços urbanos e se envolveram efetivamente no processo de urbanização de sua cidade, e quem sabe assim estejam mais sensibilizados e engajados com as questões ambientais.

\section{Referências}

BRUN, F. G. K.; LINK, D.; BRUN, E. J. O emprego da arborização na manutenção da biodiversidade de fauna em áreas urbanas. Revista da sociedade brasileira de arborização urbana, v.2, n.1, 2007.

CEMIG. Companhia Energética de Minas Gerais. Manual de arborização. Belo Horizonte: Cemig / Fundação Biodiversitas, 2011. 112 p.

GALVÃO, C. B.; MAGALHÃES-JÚNIOR, C. A. O. A relação entre as representações sociais de professores sobre Educação Ambiental e os projetos relacionados à Conferência Nacional Infantojuvenil pelo Meio Ambiente. Revista Eletrônica do Mestrado em Educação Ambiental, v. 33, n.2, p.124-141, 2016.

GUIMARÃES, M. A Dimensão ambiental na educação. Campinas: Editora Papirus,

HEIDEN, G.; BARBIERI, RL; STUMPF, ERT Considerações sobre o uso de plantas ornamentais nativas. Horticultura Ornamental, v.12, n.1, 2006.

LIMA, L. C.; PISSETTI, S. L. C.; PADILHA, M. A. C. Construção da cidadania ambiental

LORENZI, H.; SOUZA, H. M. Plantas ornamentais do Brasil(arbustivas herbáceas e trepadeiras). 3 ed. Nova Odessa, São Paulo: Ed. Plantarum, 1088p.2001. 
McHALE, M. R.; McPHERSON, E. G.; BURKE, I. C. The potential of urban tree plantings to be cost effective in carbon credit markets. Urban Forestry and Urban Greening, v. 6, p. 46-60, 2007.http//:doi.org/10.1016/j.ufug.2007.01.001

na educação infantil através da educação ambiental. Revista Gespavida, v. 3, n.5,p.106-120, 2017.

PAIVA, A. V. et al., Inventário e diagnóstico da arborização urbana viária de Rio Branco-AC. REVSBAU, v.5, n.1, p.144-159, 2010

SANTOS, J. J. A., SANTOS, A. E. S., SIlVA, A. M., SANTOS, V. C., NETO, D. C. S. Levantamento botânico de plantas utilizadas na arborização urbana de Nova Palmeira, Paraíba.Revista verde de agroecologia e desenvolvimento sustentável, v. 12, n. 5, 2017.

ZILLER, SR Espécies exóticas da flora invasoras em Unidades de Conservação. Unidades de conservação, p.34, 2006. 